\title{
The Long Term Impact of A Rainforest Experience on Chinese Students' Pro-Environmental Identity and Behavior in Macau
}

\author{
Nga Ian Tam ${ }^{*}$ \\ School of Arts, Macau Polytechnic Institute, R. de Luís Gonzaga Gomes, Macau SAR
}

\begin{abstract}
The phenomenological case study covers the limited research on Chinese students' experiences of nature in a tropical rainforest in Thailand. Macau is a very small place with only $20 \%$ of natural resources remaining but Chinese students are born to be detached from these natural environments. Their comfortable lifestyle leads to a rise of unsustainable behavior such as an increased in consumption and household waste. With numerous researches that review the benefits of nature including an enhancement in environmental friendly behavior, a $7 \mathrm{~d}$ self-funded experiential learning program in a tropical rainforest in Thailand in 2015 was initiated in fostering 12 Chinese students' pro-environmental identity and behavior. Findings show the majority of students' pro-environmental identity and behavior is enhanced and they are trying to reconnect with the natural environment more often than before.
\end{abstract}

Keywords: Experience, nature, pro-environmental identity and behavior

\section{Introduction}

Macau is a very small place, only $30.5 \mathrm{~km}^{2}$ and is made up of Macau peninsular, Taipa and Coloane. We have a population of about 650000 people and with millions of visitors we receive every year, Macau gross domestic product reaches the top tenth in the world. As Macau is becoming a tourist destination, the Macau Government Tourism Office has launched a $5 \mathrm{yr}$ plan in 2015 to promote Macau into a 'World Centre of Tourism and Leisure'. The word leisure has been traditionally linked to activities related to the natural environment and we manage to protect $20 \%$ of our natural resources, with most of them located in Coloane. However, not many young people will go to these natural places for three main reasons.

First, over half of the population in Macau resides in Macau peninsular which is around $9.3 \mathrm{~km}^{2}$. Young people enjoy living in this small compact city as when they walk down from their home, they can get everything they need within minutes of walk. With 34 gardens and 48 leisure areas, young people don't have to go to Coloane in order to walk their dogs. Second, the blooming economy increases job opportunities and many Chinese students have part time jobs. Their busy school life and jobs leave them no time to ever think of going to Coloane. Third, students in Macau love to eat and sleep and indeed, eating and sleeping is defined by Wikipedia as leisure activities. Therefore, Chinese students' identity as a city person and their association with good food, nice restaurant and concerts further disconnect them from nature.

\footnotetext{
* Corresponding author: nitam@ipm.edu.mo
} 
Chinese students association with a comfortable, easy and convenient life leads to a rise of unsustainable behavior. A survey conducted in 2015 shows 1385 high school students claimed they only know a little about knowledge in environmental protection and that they 'often and carelessly perform behavior that is not environmental" [1]. There are many researches done on the benefits of nature such as reducing depression and anxiety [2] as well as more engagement in environmental protection. Whether the government aware of these benefits or not, our city is being beautified, from greening in the pavement to the roadside and even on garbage container. However, when the urban nature is mixed with crowds of people, air pollution and even stinky garbage, can it reduce one's depression and engages one to act in a more environmental friendly behavior?

\section{Literature review}

With a lack of a natural environment in Macau, a group of Chinese students were relocated to a tropical rainforest in 2015 in order to find out whether their experience in the rainforest enhances their pro-environmental identity and behavior a year when they returned to Macau. A literature review on the benefits of nature and the value of experiential learning helps the reader to understand why experiential learning in a tropical rainforest is proposed, and why learning in a natural environment is essential to promote pro-environmental identity and behavior.

\subsection{Human and nature}

Human domination and superiority above nature centers around anthropocentric thinking in which everything in the nonhuman world exists to serve human needs and to satisfy human desire and interest [3]. When human sees no value in the nonhuman world, they don't care about the lives in the natural environment such as animal and forest and supported by Twenge et al. [4] that "saving the environment, an area purported to be of particular concern to young Millennials instead showed one of the largest declines". Moss [5] also found that children's disengagement with nature leads to nature deficit disorder as well as "social, medical and environmental problems for the future".

Many Chinese people who live in cities are disconnected from nature most of the time but extensive studies show people favor nature scenes than urban images [6]. In China, there are 50 UNESCO heritage sites and most of the sites are either carved out from rocks, lying on rocks or on mountains. These natural sites are miraculously beautiful that draw millions of visitors every year. Wilson [7] concept of biophilia indicates an "innate emotional affiliation to other living organisms" and his study show people travel far just to stroll along the sands in the Sahara desert, witnessing northern light in Norway or crowding beautiful 'Jiuzhaigou Valley Scenic and Historic Interest Area' in Sichuan province in China for reasons people can't explain. Yet, those experiences are often transformative as in Dirkx [8] mytho-poetic perspective in which powerful images that touches the soul and unconsciousness are manifested through "dreams, fantasies, myth, legends, fairy tales, stories, rituals, poetry, and performing arts, such as dance".

Human connection with nature is important as it can help to develop a sense of care for the environment and is also good for the health. Louv [2] research shows children who are exposed to nature in long period is healthier than those who do not in terms of emotion and mentality in their later years in life. Bratman et al. [12] study show paricipants expose to nature "decreased anxiety, rumination, and negative affect, and maintaind positive affect" and this is the reason why many hospital and health care center tends to use green color in their interior design as a way to foster psychological well-being. Moreover, numerous researchers such as York [10] and the others show connection with nature increased 
“creativity, awareness, wellness, environmental sensitivity, development of ecological consciousness, a sense of awe and wonder about the natural world, and personal transformation". Furthermore, research shows when one place biospheric values above their own interest, pro-environmental behavior will be fostered. Pro-environmental identity are those who connect and interact with the natural environment, with people in environmental group, with similar minds who are aware of environmental issues, or with activist who are working hard to protect the environment [11]. Pro-environmental behavior on the other hand is defined as "behavior that consciously seeks to minimize the negative impact of one's actions on the natural and built world" [12] and is encouraged by top leaders in the world. For example, one of the student learning outcome proposes by the American College Personnel Association (ACPA) Sustainability Taskforce, 2006 is "knowledge of sustainability to change their daily habits and consumer mentality" [13]. The 'Guideline for Excellence K-12 learning' for the promotion of environmental education, published by the North American Association for Environmental Education (NAAEE) is supported by United Nations Educational, Scientific and Cultural Organization (UNESCO) that environmental education is "key for respecting nature and for achieving international agendas" [14-18].

\subsection{Experiential learning}

Many higher education institutions are offering courses that connect students with nature as a number of studies and evidence points to the emotional response of nature such as fear and love is the "key point to learning and teaching" [19]. Rhode Island School of Design (RISD), one of the world's top universities of art and design in 2015 ranked by QS World University Rankings, offers a 21 credits interdisciplinary minor in 'Nature-CultureSustainability Studies (NCSS)' with over 55 classes ranging from 'Social Change in a Warming World' to 'Architecture of Utopia' to 'Biology of Animal-Human Interactions'. The community gardens in Evergreen State College, one of the 10 greenest colleges in America, is run by their students and supported by student and member fees for delivering activities and workshops that focus on ecologically-conscious farming practices and local food systems. Fels \& Bellieau [20] study show sites that can foster student imagination in arts-based learning program can improve teaching and learning and Zavestoski [21] study show a positive correlation of ecological identity and participants experience in an in-depth ecology workshop. All the studies show learning related to the environment is important and should be integrated into the curriculum.

Environmental education can take place inside the campus or in a local community but Berry [22] suggests that international/intercultural setting is better as the values embedded in the service will be particularly enhanced. Many higher education institutions are offering experiential learning programs for students such as the 'Reach Out' department in Yale University that had led trips to over 35 countries. However, experience may not foster responsibility, awareness or social engagement and engaging with others through travelling "may not be sufficient for transformative experiences" [23]. Therefore, experience that is well organized and structured is important as in Kolb [24] experiential learning theory that aims for "a systemic framework that can address twenty first century problems of learning and education" and "a theoretical perspective on the individual learning process that applied in all situation and arenas of life".

Experiential learning roots in Freire's and Dewey's theories in which "human is to engage in relationship with others and with the world" [25]. Learning in an authentic community enables student, faculty and community member to work together and learn together. Roberts [26] supports Dewey's concept that education is rests in action and Bowen's vision of a live higher education that can be "unique, varied, social, and higly 
customized to individual audiences". For the purpose of this study, experiential learning is proposed as Roberts [26] claims the live encounters of experiential learning "is for all of us on the 21 st century college and university campus".

\section{Research context}

The design department of School of Arts, Macau Polytechnic Institute, offers one elective course title 'Environmental science' but not when students can actively engaged in nature. With a lack of a working program in a natural site, relocating students to a tropical area in an overseas location is what the author had in mind as "learning in natural environments is attractive to students and encourages them to think about their environmental attitudes and behaviors" [27].

The case study was conducted from 16 to 22 December, 2015 in DinDang Natural Building Center. The center is located in a tropical rainforest in PakSong, Chumphon Province in Southern Thailand that aims to "encourage and spread knowledge on natural building and taking care of the environment by living in a self-sustainable and ecological way" [28]. Total of 12 students from the Spatial \& Exhibition design major in the design department of School of Arts, Macau Polytechnic Institute had participated in this selffunded program. Those students were selected purposively due to their knowledge in building, material and construction and their enthusiasm in participating. All students are Chinese, nine are from Macau and three are students from Mainland China.

The $7 \mathrm{~d}$ service required students to work $6 \mathrm{~h}$ a day for $5 \mathrm{~d}$ with day 6 free of work where students can relax and rest. Projects were determined by the coordinator of DinDang that involved in transporting rocks from the river, mixing concrete, gardening, splitting bamboo, making bamboo curtain, picking wild vegetables in the forest, working with clay and mud to building clay huts and so on. Students had the autonomy in selecting projects they want to do and peers they want to group with. As this is an authentic community, seven helpers from Germany, France and other countries were already there working for days and months the time when we arrived. The author worked along with the students and stayed on the same service site with them to enable me to observe their behavior throughout the project.

\section{Method}

This research seeks to find out how Chinese students experience a rainforest and the long term impact of the experience on their pro-environmental identity and behavior. A phenomenological case study is the most appropriate research design in this study. Case study and phenomenology are both qualitative research design, defined by Friesen et al. [29] as "the study of experience today with its meanings". Case study requires the researchers to collect descriptive data to determine interpretations and in this study, my onsite field notes, students' 2015 reflective journals and students' 2017 in-depth interviews were collected.

Since the students are Chinese, the in-depth interviews were conducted in Chinese. The interviews were audio-recorded with consent from the students, and the recordings were transcribed by the author and were emailed to participants for verification. Content analysis of the transcripts and journals were carried out by using a five steps approach by the author. First, the data was read-the student journal and the interview that the author had transcribed into written form - by setting the author's views of the phenomenon aside. Looking at the data in a fresh way engages the author to focus on what is reported by the students, based on their own lifeworld and perspective. While the data was read, the author 
started searching for meanings and patterns that was interesting and jotting down notes on students' insights and feelings in order to gain a whole picture of the studied phenomenon. Second, significant statements based on their relevancy to the research question was being searched. Third, the statements were selected and interpretations for themes to emerge were made. To judge which statement should go to which category requires Patton [30] dual criteria - internal homogeneity and external heterogeneity and that is when "data cohere together meaningfully" and is "identifiable" between themes. Fourth, when the themes are assigned to each cluster of data, refinement process began as subthemes may be formed under each theme. "Cross-case analysis" was conducted through "examining similarities and dissimilarities across cases" [31] to gain the uniqueness of the student journal and the interview data. The last phase involved the final integration of the data, qualities, and themes discovered in the author's own words in reviewing changes in participants' proenvironmental identity and behavior.

\section{Findings}

Several themes emerged during the analysis of students' 2015 journal and 2017 interview: (i) positive emotion of nature, (ii) fear of nature, (iii) reconnection with nature, (iv) life with nature, (v) awareness of the natural environment, (vi) self-reflection on environmental protection, (vii) reduce the use of electricity and water, (viii) reduce the use of disposable item, (ix) reuse disposable items, (x) increase in recycling and (xi) rational shopping.

One of the research questions is to find out how Chinese students experience the rainforest. In their 2015 journal, many of them talked about their excitement when they reached the rainforest and words such as 'unreal', 'surprise', 'happy' and so on were found. Although most of their perceptions of the rainforest are positive, there are negative perceptions when it involved their personal contact with nature. Words such as 'frighten', 'sickening', 'scary', 'afraid', 'disgusting' were mentioned in their journal. After a year when they returned to Macau, they continued to express the comfort of nature as well as their unwillingness in having close contact with nature.

The other research question seeks to find out the long term impact of the experience on Chinese students' pro-environmental identity and behavior. During the interview, all students reviewed an enhancement in their pro-environmental identity. When it comes to pro-environmental behavior, 11 out of 12 students claimed they have changed to be more environmental with one student saying his behavior is similar to before.

\section{Discussion}

The first research question seeks to find out Chinese students experience of nature. To understand Chinese students' experience of nature a year of their return to Macau, openended questions related to their childhood experience with nature was asked during the interview. All students claimed their interaction with nature was very limited due to the lack of greens in their city and the lack of places where they can personally connect with nature. Actually Macau has 15 walking and hiking trails all located in Taipa and Coloane, but students rarely go to these trails because to them those trails are not convenient. Mr. Pun states during the interview, "socialization can be done in Macau peninsular and I don't need to go hiking that is so troublesome". As students social life is mainly based in this vivid and busy Macau peninsular, they cannot relate anything to the word 'nature' with small trees and parks scattered around in this man made environment.

"Our society is teaching young people to avoid direct experience in nature" [2] that leads to student fear of nature and that nature is dangerous. Students' fear of nature was expressed the first day when they reached the rainforest. Female students in particular 
reacted not so positively due to the muddy roads, beds with crawling insects, and when they had to touch the mud with their hand and foot. Though there were moments when they enjoyed the rainforest especially when they were off work, the author didn't know how much they love the rainforest until the author read their journal. Most of them wrote that they missed the rainforest on the last day and some of them reviewed sadness that they had to leave. During the interview, they recalled their feeling when they were surrounded by huge and dense trees and that the feeling of being protected by the forest gave them the comfort. Mr. Choi even said he felt depressed after he returned to Macau due to the huge contrast of the environment that is filled with dust and noise, compared to the freshness and calmness of the rainforest.

The experience of a safe, non-threatening and beautiful natural environment changes students' perception that nature is dangerous and it increases their desire to reconnect with the natural environment. Moreover, students realized how tiny human is when they were in the rainforest and their lack of balance with nature is the reason of their fear and isolation of nature. A year after students returned to Macau, they were not afraid of nature as they were in the past and their fear of their personal contact with nature was turned to something positive as "a growing body of research links our mental, physical, and spiritual health directly to our association with nature-in positive ways" [2].

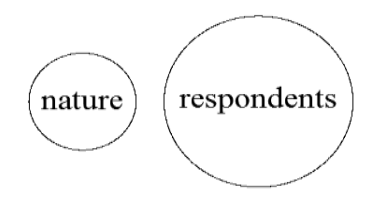

\begin{tabular}{|l} 
Before \\
\hline
\end{tabular}

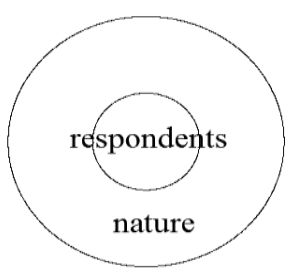

During

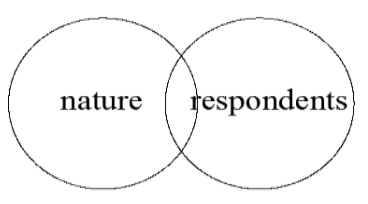

After

Rainforest Experience

Fig.1. Students' relationship with the rainforest

All students expressed their love of nature and to some of them love was turned into negative emotion. When Miss Kwok witnessed others damaging nature, she claimed she was irritated and did not like that type of behavior. Mr. Choi expressed his frustration during the interview that he was urged to leave the park in Macau while he was lying on a bench to relax. Students growing relationship with nature resulted in their positive and negative emotions of nature. Figure 1 reviewed students' relationship with nature, from dominating and separating from nature to feeling tiny and small in the rainforest, to realizing the importance of the balance of nature and human. The findings reviewed the rainforest experience resulted in students loving nature, reconnecting with nature and dreaming about going back to the rainforest sometimes in their lives.

The second research question seeks to find out the effect of the rainforest on students' pro-environmental identity and behavior. Based on students' journals and interviews, the rainforest did change their identity in regards to their awareness in environmental protection and echo numerous researchers survey that connection with nature increases "creativity, awareness, wellness, environmental sensitivity, development of ecological consciousness, a sense of awe and wonder about the natural world, and personal transformation" [10]. During the interview, students expressed how much they missed the rainforest and their love of the rainforest was turned into action when they returned to Macau. Most of them claimed going to parks and walking the trails in Coloane is something they would like to do in addition to shopping and playing computer games. Students' 
curiosity and discovery of the rainforest triggers their interest in wanting to know more about issues related to environmental protection. As the geographic location of Macau is small, their awareness can only be enhanced solely through the internet. Through google search and YouTube, students started to learn more about things they do in their daily lives and things they are interested in such as handcraft made from recycle materials and information related to their work and school projects. Students' ability in judging whether their action will cause damage to the environment is also enhanced and they also learn to think in a macro-level. For example, some students talk about having strong feelings for the polar bear whose lives are affected by the ice-melting in the Arctic Circle while others talk about wanting to volunteer to save the sea turtles.

When it comes to pro-environmental behavior, findings show 11 out of 12 students did change their behavior to be more environmental. This includes behaviors in their daily lives such as the reducing the use of electricity and water; reducing the use of plastic bags; increases in recycling; donate used items and shop smart. After analyzing the interview data, students' journal and my on-site field notes, the impact on students' proenvironmental behavior is the result of their increase awareness in environmental protection, their concern of health and wellbeing as well as the easy adoption of sustainable practice. During the interview, students claimed they have reduced the use of air-conditioner and disposable items such as the one-time wooden chopsticks and plastic forks because it is better to their health. Respondents concerned about things they use that can give them a healthier life echo Kaida [32] research that "pro-environmental behavior positively associates with present subjective well-being, which is strongly linked to future well-being; and future subjective well-being associates with pro-environmental behavior in the present". Other than health, these pro-environmental behaviors can be easily done and controlled by respondents. This supports Fishbein and Ajzen [33] study that behavior is motivated by whether one has the resources and opportunities to carry out the behavior. Moreover, Tang, Chen and Luo [16] study shows facilities can encourage recycling behavior and it holds true to students in this case study who mentioned recycle bins are easily found and more non-profit organizations are collecting used item that make recycling easier.

\section{Conclusion and implication}

All respondents reported changes in their pro-environmental identity such as having feelings for trees to putting plants at home, implementing nature into their interior design project and willing to go to parks and walking the trails more often. Pro-environmental behavior related to their daily lives is also enhanced. Therefore, the author conclude the rainforest experience did enhance Chinese students' pro-environmental identity and behavior in certain way. Most of the students in this study had completed 'Environmental science' in the design department a year before their participation but knowledge related to the rainforest was not included. Future studies may include knowledge of forestry before the experience so that students know protecting the forest can sustain their lives in city and may increase their level of involvement in environmental protection. The duration of the experience should extend to at least two weeks to a month and the service should expand to nearby community to increase students' learning and awareness in sustainable living and practice.

\section{References}

1. Associação Geral de Estudantes Chong Wa de Macau. 澳門中學生環保意識調查 研究 報告. [Investigation on environmental awareness of middle school students in Macao]. 
[Research Report]. Macau Youth Research Association. (2015). [in Chinese]. http://www.myra.org.mo/wpcontent/uploads/2015/07/\%E6\%BE $\%$ B3\%E9\%96\%80\%E4\%B8\%AD $\%$ E5\%AD $\%$ B $8 \%$ E7\%94\%9F\%E7\%92\%B0\%E4\%BF\%9D\%E6\%84\%8F\%E8\%AD\%98\%E8\%B0\%83\% E6\%9F\%A5\%E5\%A0\%B1\%E5\%91\%8A1.pdf

2. R. Louv. Last child in the woods. Chapel Hill: Algonquin Books (2008). https://www.amazon.com/Last-Child-Woods-Children-Nature-Deficit/dp/156512605X

3. M. Hathaway, L. Boff. The tao of liberation: Exploring the ecology of transformation. New York: Orbis Books (2009). https://www.amazon.com/Tao-Liberation-ExploringEcology-Transformation/dp/1570758417

4. J.M. Twenge, W.K. Campbell, E.C. Freeman. J. Pers. Soc. Psychol., 102,5:1045(2012). http://psycnet.apa.org/record/2012-05954-001

5. Moss, S. M. (2012). Natural childhood (pp. 166-171). London: National Trust.

6. E.K. Nisbet. A nature relatedness intervention to promote happiness and environmental concern. [Doctoral dissertation] Carleton University, Ottawa, Ontario] (2011). https://curve.carleton.ca/56aa4192-0e18-4646-89a1-5df41996bd03

7. E.O. Wilson. Biophilia. Cambridge: Harvard University Press (1984). http://www.hup.harvard.edu/catalog.php?isbn=9780674074422

8. J.M. Dirkx. Transformative learning and the journey of individuation. ERIC Digest No. 223. ERIC Clearinghouse on Adult Career and Vocational Education Columbus OH (2000). https://www.ericdigests.org/2001-3/journey.htm

9. G.N. Bratman, G.C. Daily, B.J. Levy, J.J. Gross. Landscape and Urban Planning, 138:41-50(2015). $\quad$ https://innerlijkefocus.nl/wp-content/uploads/Benefits-ofnature-experience-improved-affect-and-cognition.pdf

10. R.A. York. Re-connecting with nature: Transformative environmental education through the arts. [Doctoral dissertation]. University of Toronto, Toronto (2014). https://space.library.utoronto.ca/handle/1807/68404

11. S. Clayton, S. Opotow. Identity and the natural environment: The psychological significance of nature. London: Mit Press (2003).

https://mitpress.mit.edu/books/identity-and-natural-environment

12. A. Kollmuss, J. Agyeman. Environmental Education Research, 8,3:239-260(2002). https://www.tandfonline.com/doi/abs/10.1080/13504620220145401

13. ACPA. Student learning outcomes assessment materials guidebook. Washington, D.C.: National Center for Higher Education (2007).

http://www.myacpa.org/sites/default/files/ACPA_Sustainability.pdf

14. North American Association for Environmental Education. Excellence in Environmental Education: Guidelines for Learning (K-12). [Online] from https://naaee.org/sites/default/files/learnerguidelines_new.pdf (2010). [Accessed on 22 March 2017].

15.D.W. Orr. Earth in mind: On education, environment and the human prospect. Washington D.C.: Island Press (2004). https://islandpress.org/books/earth-mind

16. Z. Tang, X. Chen, J. Luo. Environment and Behavior, 43(6), 848-877(2011). https://journals.sagepub.com/doi/abs/10.1177/0013916510375681

17. M.A. Tarrant. JSIE, 14,5:433-451(2010). https://journals.sagepub.com/doi/10.1177/1028315309348737

18. United Nations Educational, Scientific and Cultural Organization. Ecological Sciences for Sustainable Development. [Online] from http://www.unesco.org/new/en/natural- 
sciences/environment/ecological-sciences/capacity-building-andpartnerships/educational-materials/ (2017). [Accessed on 27 April, 2017].

19. S.R. Kellert. Experiencing nature: Affective, cognitive, and evaluative development in children. In: Children and nature: Psychological, sociocultural and evolutionary investigations. P.H. Kahn, Jr., S.R. Kellert (Eds.). Cambridge, MA: MIT Press. (2002). p. 117-152. https://mitpress.mit.edu/books/children-and-nature

20. L. Fels, G. Belliveau. Exploring curriculum: Performative inquiry, role drama and learning. Vancouver, B.C.: Pacific Education Press (2008). http://umanitoba.ca/cm/vol15/no5/exploringcurriculum.html

21. S. Zavestoski. Constructing and maintaining ecological identities: The strategies of deep ecologies. In: Identity and natural environment. S. Clayton, S. Opotow (Eds.), Cambridge: MIT Press (2003). p. 297-316. https://mitpress.mit.edu/books/identity-andnatural-environment

22. H.A. Berry. Breaking New Ground: The Impact of International Service-Learning Programs on the Study Abroad Field. Stamford: American Institute for Foreign Study Foundation (2007). https://www.aifsfoundation.org/berry.asp

23. V. Caruana, Global Citizenship for All: Putting the "Higher" Back into UK Higher Education. In: Globalization and Internationalization in Higher Education: Theoretical, Strategic and Management Perspectives. F. Maringe, N. Foskett. London: A \& C Black (2010). p. 51-64. https://www.bloomsbury.com/uk/globalization-andinternationalization-in-higher-education-9781441132772/

24. D.A. Kolb. Experiential learning: Experience as the source of learning and development. New Jersey: Pearson FT press (2014).

https://www.amazon.com/Experiential-Learning-Experience-SourceDevelopment/dp/0133892409

25. F. Freire. Education for critical consciousness. $1^{\text {st }}$ ed. New York: Bloomsbury Academic (2013). https://www.amazon.com/Education-Critical-ConsciousnessBloomsbury-Revelations/dp/1780937814

26. J.W. Roberts. Experiential Education in the College Context: What it Is, how it Works, and why it Matters. New York: Routledge (2015).

https://www.amazon.com/Experiential-Education-College-ContextMatters/dp/1138025607

27. R. Ballantyne, J. Packer. International Research in Geographical and Environmental Education, 11,3:218-236(2002).

https://www.tandfonline.com/doi/abs/10.1080/10382040208667488

28. DinDang Natural Building Center. (2017). About Us. [Online] from https://www.idealist.org/en/nonprofit/ea05c7a2a5504e11bb28eed5fa64fdb3-dindangnatural-building-center-phato (n.d.). [Accessed on 27 April 2017]

29. N. Friesen, C. Henriksson, T. Saevi. Hermeneutic phenomenology in education: Method and practice (Vol. 4). Boston: Sense Publishers (2012).

https://www.springer.com/gp/book/9789460918346

30. M.Q. Patton. Qualitative social work: Research and practice, 1,3:261-283(2002). http://psycnet.apa.org/record/2003-05113-001

31. R. Elliott, L. Timulak, Descriptive and Interpretive Approaches to Qualitative Research. In: A handbook of research methods for clinical and health psychology. J. Miles, P. Gilbert. Oxford: Oxford University Press (2005). p. 147-159. http://www.oxfordclinicalpsych.com/view/10.1093/med:psych/9780198527565.001.000 1/med-9780198527565-chapter-11 
32. N. Kaida, K. Kaida. Environment, Development and Sustainability, 18,1:111127(2016). https://link.springer.com/article/10.1007/s10668-015-9629-y

33. M. Fishbein, I. Ajzen. Predicting and changing behavior: The reasoned action approach. UK: Psychology Press (2011). https://www.routledge.com/Predicting-andChanging-Behavior-The-Reasoned-Action-Approach/Fishbein-

Ajzen/p/book/9780203838020 